\title{
A Review on Gravitational Search Algorithm and its Applications to Data Clustering \& Classification
}

\author{
Yugal kumar \\ Dept. of Information Technology, Birla Institute of Technology, Mesra, Ranchi, Jhrakhand, India \\ Email: yugalkumar.14@gmail.com

\section{G. Sahoo} \\ Department of Information Technology, Birla Institute of Technology, Mesra, Ranchi, Jhrakhand, India \\ Email: gsahoo@bitmesra.ac.in
}

\begin{abstract}
Natural phenomenon's and swarms behavior are the warm area of research among the researchers. A large number of algorithms have been developed on the account of natural phenomenon's and swarms behavior. These algorithms have been implemented on the various computational problems for the sake of solutions and provided significant results than conventional methods but there is no such algorithm which can be applied for all of the computational problems. In 2009, a new algorithm was developed on the behalf of theory of gravity and was named gravitational search algorithm (GSA) for continuous optimization problems. In short span of time, GSA algorithm gain popularity among researchers and has been applied to large number of problems such as clustering, classification, parameter identification etc. This paper presents the compendious survey on the GSA algorithm and its applications as well as enlightens the applicability of GSA in data clustering \& classification.
\end{abstract}

Index Terms - Classification, Clustering, Gravitational Search Algorithm, Optimization, Nature Inspired Algorithm

\section{INTRODUCTION}

Nature has always been a continuous source of inspiration for researchers and scientists. A large number of algorith ms have been developed based on the natural process of evolution, laws, swarms behavior etc. Nature ins pired algorithms are the latest state of art algorith $\mathrm{ms} \&$ works well with optimization problems as well as other problems than the classical methods because classical methods are inflexible in nature. It has been proved by many researchers that nature inspired algorithms are convenient to solve complex computational problems such as to optimize objective functions [1, 2], pattern recognition [3, 4], control functions $[5,6]$, image processing [7, 8], filter modeling [9, 10], clustering [3], classification [11] etc. In last one and half decade s everal nature inspired algorithms have been developed such as Particle swarm optimization (PSO), Genetic Algorithm (GA), Simulated Annealing (SA), Ant colony optimization (ACO), Artificial Bee colony (ABC) optimization, Big Bang Big Crunch (BB-BC) etc. These algorithms show better results than classical methods in terms of accuracy, convergence computational time etc. Kirkpatrick et al. [12] proposed simulated annealing algorith $m$ based on the annealing process of metals and applied SA to solve many combinatorial optimization problems but SA suffered from convergence problem and trapped in local minima [13, 14]. In 1995, Kennady et al. [15] developed an algorithm based on the swarm behavior of birds \& fish schooling and named it Particle Swarm Optimization (PSO). This algorithm was applied to solve many optimizations such as function optimization [16] but this algorithm suffered with partial optimis $m$ and not works with scattering problems. In case of complex and complicated problems PSO algorithm suffered with optimal solution [17]. In 1975, John Holland [18] developed an algorith $\mathrm{m}$ based on the natural process of evaluation and called it genetic algorithm. Many optimization problems solved by with the help of genetic algorithm but it's suffered from parameter tuning problem due to complicated crossover \& mutation operator and convergence speed [19]. ACO was developed by the Dorigo [20] in 1992 based on the behaviors of real world ants. This algorithm applied to solve many optimization problems such as TSP [21], Graph Coloring [22], Network Routing [23] etc. ACO algorith $m$ is sometimes suffered from selection bias [24] and convergence $[25,26]$ problem. Devis Karbooga et al. [27] in 2006 proposed ABC algorithm based on the behavior of hooney Bees i.e. capabilities of Bees to find the food source for numerical optimization problems. Later on ABC algorithm has widely used to solve other problem such as multi-dimensional numeric problems [28], real-parameter optimization [29, 30], constrained numerical optimization problems [31] etc. Derv is Karaboga \& Beyza Gorkemli et al. [8] provided comprehensive description about the $\mathrm{ABC}$ algorith $m$ and its application in various fields as well as hybridization of $\mathrm{ABC} \&$ its variants. There are some drawbacks of ABC algorith $m$ such as it requires large number of objective function evaluations [32], handling complex multimodal functions, functions with narrow curve valley, convergence slow down due to stochastic nature [30] and weak exploitation feature [33]. Os man K. Erol et al. [34] 
in 2006 proposed a new algorithm Big Bang Big Crunch (BB-BC) based on the big bang theory (Theory of Evolution of Universe) for optimization problems. BB$\mathrm{BC}$ algorithm is used to solve large numbers of optimization problems such as multi modal optimization problem [35], multi-objective optimization problem [36], clustering [37] etc. A brief description about the nature inspired algorith ms has been given above that are used to solve the optimization problems but till date there does not exists any algorithm that can solve the entire optimization problems exactly.

The gravitational search algorithm is the latest nature inspired algorithm proposed by E. Rashedi [38] to solve the optimization problems based on the Law of gravity. Many researchers has applied the gravitational search algorithm on large numbers of problems because it requires only two parameters and having ability to find near global optimu m solution and provides better results as compare to other nature inspired algorith ms. Figure 1 depicts the applications of the gravitational search algorith $m$ in various domains. The objective of this paper is to provide comprehensive survey for the researchers which are doing research in the field of optimizing problems (gravitational search algorithm), swarm intelligence and nature inspired algorithms. The first objective of this paper is to find out the number of algorithms that are derived from the original GSA to solve the optimization problems as well as to find out the application of gravitational search algorithm in various domains such as pattern recognition, power system, data mining, classification \& clustering and how many algorithms are proposed by using gravitational search algorithm plus other nature inspired techniques such as GA, PSO, SA etc. (Hybrid GSA). The second objective of this paper is to find out the significance of Gravitational algorithm in clustering and classification problems. In present time, large number of algorithms based on the behavior of swarms \& natural processes are used to solve these problems and this paper also provides the comparisons of GSA with swarm based algorithms for clustering and classification problems.

The rest of paper is organized as follows. Section II gives the detail about GSA. Section III describes variants and modifications in GSA. The hybridization of GSA with other techniques is discussed in section IV. Section $\mathrm{V}$ and VI focus the application of GSA algorithm in clustering and classification. These sections are followed by conclusion of paper.

\section{GRAVIT ATIONAL SEARCH ALGORITHM}

The gravitational search algorithm is the latest nature inspired population based stochastic search algorithm which is widely used to solve the optimization problems. E. Rashedi [38] initially proposed gravitational search algorith $m$ to solve the optimization problem particularly for non linear problems. The gravitational search algorithm is based on Newton's theory. Newton's law of gravity states that every particle attracts another particle by means of some gravitational force [39, 40]. The gravitational force between two particles is directly proportional to the product of their masses and inversely proportional to the square of the distance between them [39]. In proposed algorithm particles considered as objects and their performance has evaluated with their masses. In GSA, each particle has associated with four specifications: particle position, its inertial mass, active gravitational mass and passive gravitational mass. The position of particles provides the solution of problem while fitness function is used to calculate the gravitational and inertial masses. Every population based algorithm has two capabilities: exploration and exploitation. This algorithm uses exploration capability at the beginning to avoid local optimum problem and after that exploitation. A time function named as Kbest particle/agent is used to attract other particles. The performance of GSA is improved by controlling exploration \& exploitation. The value of Kbest function decreases with time linearly and at last only one agent will be there with heavy mass that represents final solution. Step by step procedure of Gravitational Search Algorithm is given below:

- Identification of search space.

- Generate Initial population.

- Evaluate fitness function for each particle in population.

- Update the gravitational constant value.

$$
\begin{aligned}
\mathrm{G}(\mathrm{t})=\mathrm{G}\left(\mathrm{G}_{0}, \mathrm{t}\right), \operatorname{Best}(\mathrm{t}) & =\min _{i \in\{1, \ldots, N\}} \text { Fit }{ }_{i}(t) \\
\operatorname{Worst}(\mathrm{t}) & =\max \underset{i}{\operatorname{Fit}(\ldots . N}(t)
\end{aligned}
$$

- Calculate the total force in different direction (M) and Acceleration (a) by following equations:

$$
\begin{gathered}
\mathrm{M}_{i}(t)=\frac{\mathrm{m}_{i}(t)}{\sum_{j-1}^{N} \mathrm{~m}_{i}(t)} \text { Where } \mathrm{m}_{i}(t)=\frac{\mathrm{Fit}_{i}(t)-\operatorname{Worst}(t)}{\operatorname{Best}(t)-\operatorname{Worst}(t)} \\
\text { Acceleration } a_{i}^{d}(t)=\frac{F_{i}^{d}(t)}{M_{i j(t)}}, \text { where } F_{i}^{d}(t)= \\
\sum_{j=1, j \neq i}^{N} \operatorname{rand}_{j} F_{i j}^{d}(t)
\end{gathered}
$$

- Update the particle velocity and position. Velocity and position of particle is calculated by following equations:

$$
\begin{gathered}
\text { Velocity }{ }_{i}^{d} V(t+1)=\operatorname{rand}_{i} \times{ }_{i}^{d} V(t) \times{ }_{i}^{d} a(t) \\
\text { Position } X_{i}^{d}(t+1)=X_{i}^{d}(t)+V_{i}^{d}(t+1)
\end{gathered}
$$

- Stopping criteria (repeat until stopping criteria met).

The performance of the GSA is evaluated with PSO, RGA and CFO including twenty three benchmark functions such as uni-modal test function, multimodal test function etc. and GSA provides better result with most of the functions. But the proposed GSA algorithm solves the problems in continuous valued space. Large number of algorithms derived from gravitational search algorithm to solve different problems. The Figure 2 provides the percentage of algorithms (original GSA, GSA Variants \& Hybridized GSA) that was derived from the gravitational search algorith $m$ to solve the different 
problems till date as well as to improve the statistics of original GSA.

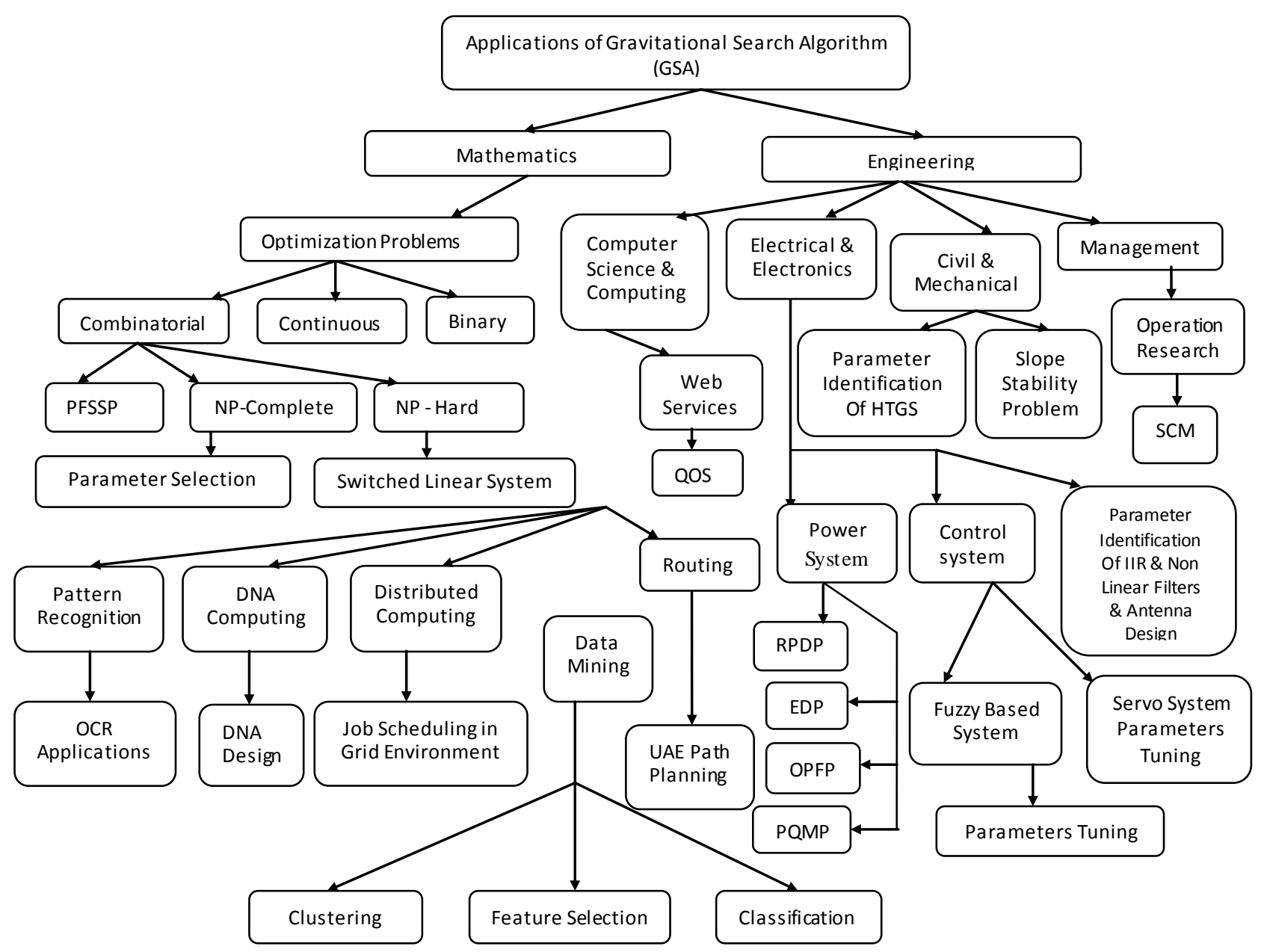

Fig. 1. Applicability of Gravitational Search Algorithm in different domains
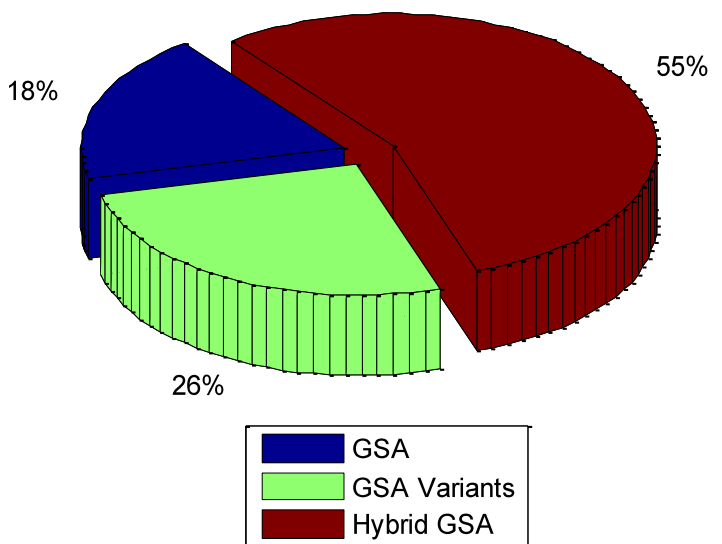

Fig. 2. Statistics of Gravitational Search Algorithm

\section{GSA VARIANTS, COMPARISONS AND MODIFICATIONS}

Initially, GSA was proposed to solve the continuous optimization problems but later on many researchers also applied GSA to solve other optimization problems such as binary optimization problems, combinatorial optimization problems etc and generate the success or of GSA. Es mat Rashedi [41] has developed the Binary version of the original GSA for binary optimization problems in which updating position means to switch between 0 and 1 rather than contiguous. Binary problems are represented in binary space rather than real space such as hypercube \& compare the performance of BGSA using 23 minimization \& 2 maximization benchmark function with GA and Binary PSO. BGSA provides remarkable result as compared to others algorith ms. To explore the "near global optimum" GSA takes into account two parameters i.e. swarm size and gravitational coefficient which specifies the searching ability of GSA such as premature convergence, speed, capturing candidate solution, population exploration etc. To solve the multi objective problems Hamid Reza Hassanzadeh et al. [42] have proposed another variant of GSA i.e. Multi Objective GSA (MOGSA). The proposed algorithm is used pareto optimality function with standard GSA to solve the multi objective problems and the performance of MOGSA evaluates with SMPSO, 
MOGA2 and PAES using spacing \& gravitational distance criteria in which MOGSA provides better result in terms of distribution of solutions but it takes more time as compare to another method while the another techniques require niching method must be apply for distribution of solutions. The original GSA is not suitable for more complicated task basically it is used to solve the non linear benchmark functions, to overcome this problem Sarafrazi et al. [43] defined a new operator for GSA named as "disruption" to increases the exploration and exploitation ability of gravitational search algorith $\mathrm{m}$. A threshold value parameter is used by author to increases the performance of the original GSA as well as to increases the global optimum property of GSA and generates good candidate solutions, which can be achieved by measuring the ratio of distance between the mass $\mathrm{k}$ and nearest neighbors. The performance of proposed GSA compare with original GSA, PSO and RGA with twenty three benchmark functions. The proposed algorithm provides better results than others and also avoids premature convergence problem of original GSA. M. Soleimanpour moghadam [44] et al. has proposed Quantum based GSA which is a modified version of GSA. QGSA is based on dynamics of Quantum. In original GSA position of object and its velocity cannot be found simultaneously to overcome this QGSA actuates the mass of object by waveform instead of position and velocity. QGSA provides better results over original GSA. The QGSA algorithm suffers with "diversity loss" problem in collecting the masses of objects. Radu et al. [45] has proposed a new GSA to reduced parametric sensitivity of Fuzzy based control system for optimal tuning. The proposed algorithm is constructed from original GSA by applying three modifications: define constraint regarding system, modify deprecation equation of gravitational constant and extended symmetrical method. The performance of algorithm evaluates with performance index and algorith $m$ provides better performance with parametric variations of controlled process. To increase the searching ability of GSA and high convergence rate Nihan Kazak et al. [46] has developed a new version of GSA i.e. Modified GSA (MGSA). The proposed algorith $m$ is based on the original GSA and concept of satellite agent. The performance of MGSA evaluates with three benchmark functions and compare with original GSA. The MGSA provides better result than GSA. To increases diversity of mass collection and avoid local minima Mohadeseh Soleimanpour moghadam \& Hossein Nezamabadi pour [47] have proposed Improved QGSA which is a new version of QGSA. In improved QGSA the fitness function of QGSA has replaced by a new fitness function. The performance of IQGSA evaluated with seven minimization benchmark functions and compared with original GSA \& QGSA in which IQGSA has given better results than others. To improve computational cost of original GSA Naji et al. [48] have developed a multi agent based GSA which is new version of GSA. In multi agent based GSA, operations have performed in parallel rather than sequential. The performance of multi agent based GSA evaluated using six bench mark functions and compared with original GSA. The multi agent based GSA (2.72 for 600 masses) provided better performance than original GSA (3.54 for 600 masses). The multi agent based GSA has ability to solve the optimization proble ms with non convex objective functions and improved sensitivity feature.

\section{GSA HYBRIDIZATION AND APPLICATIONS}

The hybridization of an algorithm pretends the algorith $m$ more powerful and enhances the capabilities of an algorithm. Due to hybridization, coverage area of algorithms exacerbates and it can wrap more problems. The GSA is also hybridizes with conventional and swarm based algorithms to enhance its capabilities. To solve permutation flow shop problem (PFSSP) Xiangtao Li [49] et al. has proposed "SIGSA" a new hybrid algorithm based on the GSA and SA. To design the proposed algorithm for PFSSP there were two challenges, firstly how to make GSA applicable for PFSSP and second trap in local minima problem. First obstacle was removed by using LRV rule and second was removed by using SA \& IIS based local search. With the help of SA \& IIS local search, four variants of GSA are defined: NGSA, SGSA, IGSA and SIGSA. To evaluate the performance of SIGSA with PFSSP, twenty nine problems of two classes of PFSSP are taken and compare the performance of SIGSA with NGSA, SGSA \& IGSA as well as PSOMA \& PSOVNS in which SIGSA provides better performance with all other methods. To avoid slow convergence speed of GSA Seyedali Mirjalili et al. [50] has proposed a new hybrid algorithm PSOGSA which is based on the PSO and GSA for function optimization problems. The proposed algorith $\mathrm{m}$ is used the global best i.e. "gbest" concept of PSO in GSA to find out best current position among all current positions. The performance of PSOGSA evaluates with twenty three benchmarks functions and compares with Std. PSO \& Std. GSA in which PSOGSA performs very well with most of functions as compare to Std.PSO \& Std.GSA and provides faster convergence speed. To improve side lobe levels in concentric ring array A. Chatterjeeet et al. [51] has applied the GSA for synthesis of thinned scanned concentric ring array antenna. The performance of GSA evaluates with fitness value \& computational time and compare with Modified PSO in which GSA provides better results than Modified PSO. The ability to solve the optimization problems with minimizes discrete time objective function Radu-Emil Precup et al. [52] has proposed a new version of GSA for tuning the fuzzy control systems. The new version of GSA is derived from the original GSA by modification in deprecation equation and adding constraint regarding system in original GSA. The proposed algorithm provides significant improvement in performance indices and covers large number of control plants but the algorithm could not promised global optimum and minimum sensitivity. To solve the partner selection problem with due date constraint Jianhua Xiao et al. [53] has proposed a new 
hybrid gravitational chaotic search algorithm (GCSA) based on the GSA and chaotic local search. The performance of GCSA compares with GSA, PSO, GA and $\mathrm{B} \& \mathrm{~B}$ in which GCSA provides better performance than others algorithms using cost criteria and avoids trapping in local optional solution in last iterations as well as increases convergence rate. J. P. Papa et al. [54] have proposed a new hybrid algorithm OPF-GSA based on GSA \& optimum path forest classifier for feature selection task and compares the performance of OPFGSA with OPF-PSO, OPF-PCA, and OPF-LDA on the behalf of accuracy, numbers of features selected \& time required in which OPF-GSA provides better performance in terms of number of features selected but requires more execution time than OPF-PSO. To satisfy/overcome "initial/boundary conditions" M. Ghalambaz et al. [55] has proposed a new hybrid algorith $m$ HNNGSA based on artificial neural network and GSA for wessinger's equation. In proposed method, GSA is used to actuate the adjustable parameter and trained the multi layer neural network. The performance of HNNGSA compares with Euler, improved Euler and Runge-Kutta in which HNNGSA provides better result than other methods. Chaoshun Li et al. [56] has proposed a hybrid algorith $m$ IGSA based on GSA \& PSO to identify the parameter for hydraulic turbine governing system. The proposed algorithm is differed by two ways; firstly the search technique of PSO was used with GSA to found global optimum and secondly define a new objective function. The performance of IGSA compares with GA, PSO \& GSA in which IGSA provides higher frequency than others Jianhua Xiao and Zhen Cheng [57] has applied the gravitational search algorithm on DNA sequences optimization problem to compute good DNA sequences and compares the performance of GSA with Delton Algorith m (GA) for DNA design in which GSA provides better result than GA on the behalf of continuity, $\mathrm{H}$ measure and similarity criteria parameters. To solve the parameter estimation problem of IIR and Non linear rational filters Saeid Saryazdi et al. [58] has applied the GSA for filter modeling in which GSA works as heuristic search algorithm and compares the performance of proposed method with PSO \& GA with unimodal function, multimodal function \& complexity of problem i.e. added noise in which proposed algorithm provides better result without sucked in local optima. To improve the "fuel cost result" Serhat Duman et al. [59] has applied the GSA to solve the "Economic Dispatch problem" for electrical power systems. The performance of proposed method evaluates with three test system and compares with artificial immune system, Meta evolutionary programming, genetic algorithm, IPSO, AIACO and HPSO among these methods, GSA provides minimum fuel cost. To solve parameter identification problem of chaotic system, Chaoshun Li et al. [60] has proposed a new hybrid algorithm CGSA based on the chaotic local search \& GSA and compared the performance of CGSA with PSO, GSA \& GA in which CGSA provides better result than others. To minimize the objective function (Discrete time weighted sum of control error \&Output sensitivity) of fuzzy based servo control systems RaduEmil Precup et al. [61] has proposed a novel adaptive gravitational search algorithm based on original GSA and BGSA. The proposed algorithm is different from the earlier algorith $m$ proposed by Radu-Emil Precup et al. [45] \& Radu et al. [52]. In novel adaptive gravitational search algorithm two deprecation laws are defined for gravitational coefficient which is derived from adaptive PSO. The adaptive GSA provides reduced time constant sensitivity with a new formulation of Takagi-Sugeno Proportional Integrated Fuzzy Controllers (T-S PI-FCs). The back propagation algorithm for neural network sometime provides local minimum convergence rather than global minimum. So, to overcome local minimum convergence problem of back propagation in neural network Lucian-Ovidiu Fedorovici et al. [62] has applied GSA with back propagation to train the convolution neural network for OCR applications because GSA has ability to provided near global optimum solution and evaluated the performance of embedded GSA in convolution neural network with back propagation technique to classical back propagation algorithm. The embedded GSA provides better result as compares to classical BP in terms of convergence and recognitions rates. To determine the behavior of GSA with nonlinear problems S. Duman et al. [63] has applied the GSA algorith $m$ to find the optimal solution for "reactive power dispatch problem". The performance of proposed algorithm evaluates with IEEE $30,57 \& 118$ bus power system using three cases i.e. minimization of system real power, improvement voltage profile \& enhancement of voltage stability and compared with $\mathrm{BBO}, \mathrm{PSO}, \mathrm{DE}$, CLPSO, CGA, AGA, SPSO, L-DE etc. The proposed algorith $m$ provides robust and better quality result than other methods to solve RPD problem. Serhat Du man et al. [64] (2012) are also proposed a new method based on GSA for "optimal Power Flow problem" in power system to find optimal solution due to the ability of GSA adjust the accuracy of search itself. The performance of proposed GSA method evaluates with IEEE 30 Bus power system including six different cases and compared with BBO, PSO, DE, Improved GA, Gradient Descent, EADDE and Enhanced GA using two parameters i.e. average fuel cost and simulation time in which proposed GSA method provides best performance using both of parameters. To solve parameter quality placement problem in power system Ahamad Asurl Ibrahim et al. [65] have proposed a hybrid algorithm QBGSA based on concept of Quantum and BGSA with improved search strategy \& convergence speed. Performance of QBGSA evaluates with radial 18 bus distribution system \& IEEE 118 bus system using bolted three phase, double line to ground \& single phase to ground faults using iteration, fitness function \& standard deviation parameters and compares with BGSA, OBPSO \& BPSO in which QBGSA provides better performance than others in terms of fitness function \& standard deviation but suffers from slow convergence rate. To improve slow convergence rate and avoid trap in local minima problem of GSA Seyed Ali Mirjalili et al. [66] has proposed a new hybrid 
algorithm PSOGSA based on the GSA \& PSO in which PSOGSA implemented as new training method for Feed forward Neural Networks. Statistics shows that the PSOGSA provides better performance as compares to PSO and GSA. To detect the minimu $m$ factor of safety \& reliability index in deterministic and probabilistic slope stability analysis Mohammad Khajehzadeh et al. [67] (in press) has proposed a hybrid Modified gravitational search algorithm (MGSA) based on GSA \& velocityclipping technique with time varying maximu m velocity. Firstly, the performance of proposed algorithm evaluates with five bench mark functions i.e. unimodal, multimodal etc. and compares with original GSA using accuracy, stability, convergence rate \& robustness parameters in which MGSA provides better performance than GSA. After that MGSA has applied on slope stability analysis to determine safety \& reliability index factor and compared with MVFOSM with Spencer method \& non circular slip surface, MVFOSM with Spencer method \& non circular slip surface by direct search, AFOSM with Spencer method \& non circular slip surface by PSO, AFOSM with Spencer method \& non circular slip surface by MPSO, AFOSM with M-P method \& non circular slip surface by original GSA in which MGSA provided minimum value for minimum factor of safety \& reliability index than others. To overcome computational complexity, optimality and convergence in hybrid system identification Hamed Sadeghiet et al. [68] has proposed a new version of GSA based on GSA \& idea of sparse optimization from the field of sparse signal recovery to identification of switched linear system from inputoutput data and parameter extraction for sub models. The proposed algorithm provides better performance. To enhance the global search strategy for path planning problem in UAV, LI Pei et al. [69] has applied the hybridize GSA plus PSO algorithm for this problem and compared the performance of proposed algorithm with original GSA \& PSO in which proposed algorithm provides better performance than others. The application of GSA in clustering and classification discuss in separate section.

Discussion: Lot of algorithms have been developed by the researcher based on the gravitational search algorith $m$ to improve the capabilities of GSA, increases the coverage area of GSA, overcome the limitations of some existed algorithms etc. and compared the performance of GSA to others techniques such as PSO, GA, DE, BBO, $\mathrm{ABC}$ etc. in which GSA provided better performance than others. The Table 1 provide the year wise development in the field of gravitational search algorith $\mathrm{m}$ as well as the problems addressed by the GSA \& GSA based algorithms with performance matrices.

Table1. List of proposed algorithm using GSA and its variants

\begin{tabular}{|c|c|c|c|c|}
\hline Year & Author & Algorithm & Problem & Performance Metrics \\
\hline 2009 & Rashedi et al (2009) & GSA & $\begin{array}{l}\text { Optimization problems } \\
\text { in continuous space }\end{array}$ & $\begin{array}{l}23 \text { Non linear benchmark functions } \\
\text { i.e. unimodal, multi model }\end{array}$ \\
\hline 2010 & Rashedi et al (2010) & BGSA & $\begin{array}{l}\text { Binary optimization } \\
\text { Problems }\end{array}$ & $\begin{array}{l}23 \text { Minimization and } 2 \text { maximization } \\
\text { benchmark functions }\end{array}$ \\
\hline 2010 & $\begin{array}{l}\text { Hamid Reza Hassanzadeh } \\
\text { et al (2010) }\end{array}$ & MOGSA & $\begin{array}{l}\text { Multi Objective } \\
\text { optimization problems }\end{array}$ & Spacing \& gravitational distance criteria \\
\hline 2010 & Xiangtao Li et al (2010) & SIGSA & $\begin{array}{l}\text { Permutation flow shop } \\
\text { scheduling problem }\end{array}$ & $\begin{array}{l}29 \text { Problems of two classes of PFSSP } \\
\text { such as car } 1 \text {, car } 2 \text { to car8 etc. }\end{array}$ \\
\hline 2010 & A. Chat terjeeet al (2010) & GSA & $\begin{array}{l}\text { To improve Side lobe in concentric } \\
\text { ring arrays(Antenna) }\end{array}$ & Fitness Value \& Computational Time \\
\hline 2010 & Seyedali Mirjalili et al (2010) & PSOGSA & $\begin{array}{l}\text { To avoid slow convergence due to } \\
\text { memory less feature of GSA }\end{array}$ & $\begin{array}{l}23 \text { Non linear benchmark functions } \\
\text { i.e. unimodal, multi model }\end{array}$ \\
\hline 2011 & $\begin{array}{l}\text { Jianhua Xiao and } \\
\text { Zhen Cheng }(2011)\end{array}$ & GSA & $\begin{array}{l}\text { DNA sequences } \\
\text { optimization problem }\end{array}$ & $\begin{array}{l}\text { Continuity, } \\
\text { H- measure and Similarity }\end{array}$ \\
\hline 2011 & S. Sarafrazi et al (2011) & Improved GSA & $\begin{array}{l}\text { To increases the exploration } \\
\text { and exploit ation ability }\end{array}$ & 23 Non linear benchmark functions \\
\hline 2011 & $\begin{array}{l}\text { M. Soleimanpour-moghadam } \\
\text { et al (2011) }\end{array}$ & QGSA & $\begin{array}{l}\text { Position and Velocity of } \\
\text { an object in GSA }\end{array}$ & Unimodal \& mult imodal \\
\hline 2011 & Saeid Saryazdi (2011) & $\begin{array}{l}\text { GSA worked as } \\
\text { heuristic search }\end{array}$ & $\begin{array}{l}\text { Parameter est imation problem of IIR } \\
\text { and Nonlinear rational filters }\end{array}$ & $\begin{array}{l}\text { Unimodal function, multimodal } \\
\text { function \& complexity of problem }\end{array}$ \\
\hline 2011 & Jianhua Xiao et al (2011) & GCSA & $\begin{array}{l}\text { Partner selection problem } \\
\text { with due date constraint }\end{array}$ & Cost criteria \& convergence rate \\
\hline 2011 & Radu-Emil Precup et al (2011) & $\begin{array}{l}\text { GSA with } \\
\text { modified } \\
\text { deprecation } \\
\text { equation }\end{array}$ & $\begin{array}{l}\text { Tuning the fuzzy } \\
\text { control systems }\end{array}$ & Performance indices \\
\hline 2011 & Radu-Emil Precup et al (2011) & $\begin{array}{l}\text { GSA with three } \\
\text { modifications }\end{array}$ & $\begin{array}{l}\text { To improve parametric } \\
\text { sensitivity }\end{array}$ & Performance indices \\
\hline
\end{tabular}




\begin{tabular}{|c|c|c|c|c|}
\hline 2011 & Serhat Duman et al (2011) & GSA & $\begin{array}{l}\text { Economic Dispatch } \\
\text { problem }\end{array}$ & Three test system \\
\hline 2011 & J. P. Papa et al (2011) & OPF-GSA & Feature selection Task & Number of features selected \\
\hline 2011 & M. Ghalambaz et al (2011) & HNNGSA & $\begin{array}{l}\text { To solve wessinger's } \\
\text { equation }\end{array}$ & $\ldots$ \\
\hline 2011 & Chaoshun Li et al (2011) & IGSA & $\begin{array}{l}\text { To identify theparameter for } \\
\text { hydraulic } \\
\text { turbine governing system }\end{array}$ & Frequency \\
\hline 2011 & Abdolreza Hatamlou et al (2011) & GSA & Dat a clustering & $\begin{array}{l}\text { Sum of intra clusterdistance } \\
\text { and Standard deviation }\end{array}$ \\
\hline 2011 & Minghao Yin et al (2011) & IGSAKHM & $\begin{array}{l}\text { Slow convergence problem } \\
\text { of GSA in clustering }\end{array}$ & $\begin{array}{l}\text { F- measure, run time, mean } \\
\text { and st andard deviation }\end{array}$ \\
\hline 2011 & Abdolreza Hat amlou et al (2011) & GSA-HS & Clustering & $\begin{array}{l}\text { Sum of intra cluster distance and } \\
\text { center of corresponding cluster }\end{array}$ \\
\hline 2011 & Soroor Sarafrazi et al (2011) & GSA-SVM & $\begin{array}{l}\text { To increases classification } \\
\text { accuracy in Binary Problems }\end{array}$ & Std. Dev., Mean, Max.\& Min. \\
\hline \multirow{2}{*}{2012} & \multirow{2}{*}{ Nihan Kazak et al (2012) } & \multirow{2}{*}{$\begin{array}{l}\text { Modified GSA } \\
\text { (MGSA). }\end{array}$} & \multirow{2}{*}{$\begin{array}{l}\text { To increases searching } \\
\text { and convergence rate }\end{array}$} & 3 Benchmark functions \\
\hline & & & & Such as unimodal, multimodal \\
\hline 2012 & $\begin{array}{l}\text { Mohadeseh Soleimanpour } \\
\text { et al (2012) }\end{array}$ & Improved QGSA & Diversity loss problems & Unimodal \& multimodal \\
\hline 2012 & $\begin{array}{l}\text { Lucian-Ovidiu Fedorovici } \\
\text { et al (2012) }\end{array}$ & GSA with BP & OCR applications & Convergence and recognitions rates \\
\hline 2012 & Nanji H. Ret al (2012) & $\begin{array}{l}\text { multi agent } \\
\text { based GSA }\end{array}$ & $\begin{array}{l}\text { Comput ational cost of } \\
\text { original GSA }\end{array}$ & $\begin{array}{l}\text { Six bench mark functions } \\
\text { such as unimodal, multimodal }\end{array}$ \\
\hline 2012 & $\begin{array}{l}\text { Radu-Emil Precup } \\
\text { et al(2012) }\end{array}$ & Adaptive GSA & $\begin{array}{l}\text { To minimize the } \\
\text { objective function }\end{array}$ & Sensitivity \\
\hline 2012 & S. Duman et al (2012) & GSA & $\begin{array}{l}\text { Reactive power } \\
\text { dispatch problem }\end{array}$ & $\begin{array}{l}\text { Minimization of system real power, } \\
\text { improvement voltage profile \& } \\
\text { enhancement of voltage }\end{array}$ \\
\hline 2012 & Serhat Duman et al (2012) & GSA & $\begin{array}{l}\text { Optimal Power } \\
\text { Flow problem }\end{array}$ & $\begin{array}{l}\text { IEEE } 30 \text { Bus power system including } \\
\text { six different cases }\end{array}$ \\
\hline 2012 & Chaoshun Li et al (2012) & CGSA & $\begin{array}{l}\text { Parameteridentification problem of } \\
\text { chaotic system }\end{array}$ & \\
\hline 2012 & $\begin{array}{l}\text { Abdolreza Hatamlou } \\
\text { et al (2012) }\end{array}$ & GSA-KM & $\begin{array}{l}\text { Clustering problem(For improve } \\
\text { searching capabilities of GSA) }\end{array}$ & Number of steps and cost \\
\hline 2012 & Chaoshun Li et al (2012) & GSAHCA & $\begin{array}{l}\text { Identification of T-S } \\
\text { fuzzy model }\end{array}$ & Model accuracy \\
\hline 2012 & Hossein Askari et al (2012) & Intelligent GSA & Classification of data & $\begin{array}{l}\text { Accuracy, minimum, maximum } \\
\text { and average score of recognition }\end{array}$ \\
\hline 2012 & $\begin{array}{l}\text { Ahmad Asurl Ibrahim } \\
\text { et al (2012) }\end{array}$ & QBGSA & $\begin{array}{l}\text { Power quality monitor placement } \\
\text { (PQMP) problem }\end{array}$ & $\begin{array}{l}\text { Radial } 69 \text { bus distributed system and } \\
\text { IEEE } 118 \text { bus system with Bolted three } \\
\text { phase, Double line to ground and Single } \\
\text { phase to ground }\end{array}$ \\
\hline 2012 & $\begin{array}{l}\text { Hamed Sadeghiet } \\
\text { et al (2012) }\end{array}$ & $\begin{array}{l}\text { GSA with sparse } \\
\text { optimization }\end{array}$ & $\begin{array}{l}\text { Identification of switch linear system } \\
\text { and Parameter estimation }\end{array}$ & $\begin{array}{l}\text { Statistical Robustness under excitation, } \\
\text { noise and switching sequence }\end{array}$ \\
\hline 2012 & $\begin{array}{l}\text { Mohammad Khajehzadeh } \\
\text { et al (2012) }\end{array}$ & MGSA & Slope Stability Analysis & $\begin{array}{l}\text { Minimum factor of safety } \\
\text { and reliability index }\end{array}$ \\
\hline 2012 & $\begin{array}{l}\text { Abbas Bahrololoum } \\
\text { et al (2012) }\end{array}$ & $\begin{array}{l}\text { prototype } \\
\text { classifier } \\
\text { based on GSA }\end{array}$ & Data classification & $\begin{array}{l}\text { Average misclassification } \\
\text { percentage error }\end{array}$ \\
\hline 2012 & Li Pei et al (2012) & $\begin{array}{l}\text { GSA with PSO } \\
\& \text { DE(IGSA) }\end{array}$ & $\begin{array}{l}\text { Routing (Path planning } \\
\text { for UAE) }\end{array}$ & Cost of threats \& Evolution Curve \\
\hline 2013 & Soroor Sarafrazi et al (2013) & GSA-SVM & $\begin{array}{l}\text { Parameter Setting of SVM \& } \\
\text { Increased accuracy(Classification) }\end{array}$ & $\begin{array}{l}\text { Accuracy } \\
\text { (Mean \& Standard Deviation) }\end{array}$ \\
\hline
\end{tabular}

V. GSA IN ClUSTERING
Clustering is the process to expose previously undiscovered patterns from datasets and assemble data 
entities into disjoint clusters such that entities of each cluster are similar. Clustering techniques have been employed in many areas such as pattern recognition [3, 4], information retrieval [70,71], data mining [72, 73], and many more. Large number of nature inspired algorith ms is applied on the data clustering problem such as ABC [11], PSO [74], KMH [75], ACO [76], K-means [77], BB-BC [34] etc. There does not exists a single algorithm that is adequate to solve all of requisite for clustering problems due to diversity of clustering problems, different data type and intention of clustering. This paper also enlightens the application of GSA for data clustering problems. Abdolreza Hatamlou et al. [78] has proposed a gravitational search algorithm for data clustering applications and compared the performance of proposed algorithm with PSO, GA and K-means. Proposed algorith $m$ provides the viable and robust result for data clustering as compares the PSO, GA and $\mathrm{K}$ - means using sum of intra cluster distance and standard deviation parameters. This algorithm provides the good searching ability to find global optimum but in the last iterations the performance of algorithm suffers due to slow searching speed. To improve the searching ability of GSA, Abdolreza Hatamlou and Salwani Abdullah et al. [79] have proposed a hybrid algorithm GSA-KM based on the GSA \& K- means for clustering problem because $\mathrm{k}$-means is simple and fast algorithm. The hybrid algorith $\mathrm{m}$ provides better performance in comparison of original GSA by two ways. First, the numbers of steps require for iteration $\&$ evaluate the objective function to find global optimu m was reduced, its increased execution speed of hybrid algorithm. Second, due to the use of kmeans with GSA, a good candidate solution is generated for initial population so that near global optimum searched in more promising search space and provided a better quality solution as compared to original GSA. To reduce the slow convergence speed of GSA, Minghao Yin et al. [80] has proposed new algorithm IGSAKHM based on the IGSA and K-harmonic means for clustering problem. KHM is easily sucked in local optima but fast convergence speed as compare to GSA. On the other hand IGSA has ability to find near global optimum solution easily but suffered with slow convergence rate. The performance of IGSAKMH evaluates with $\mathrm{F}$ measure, run time, mean and standard deviation parameters and compares with $\mathrm{KMH}$ and PSOKMH in which IGSAKMH provides better performance with $\mathrm{F}$ measure, mean \& standard deviation than others but execution time of IGSAKMH algorith $m$ longer than the $\mathrm{KMH}$. So, the application where run time is critical parameter, IGSAKMH will not work efficiently. To reduce convergence in local optima of K-Means algorith m, Abdolreza Hatamlou et al. [37] has proposed a new hybrid algorithm GSA-HS based on GSA and Heuristic search technique. In the proposed algorithm, initial population is generated by the GSA after that heuristic search technique is applied to exploration of population. The performance of GSA-HS evaluate with two parameters i.e. sum of intra cluster distance and center of corresponding cluster including four bench mark datasets and compare with K-Means \& PSO in which GSA-HS provides better results than others. To improve the "fuzzy space partition" \& identification of "premises parameter" Chaoshun Li et al. [56] has developed a new hybrid GSA based on hyper plane clustering algorithm (GSAHCA) for identification of T-S fuzzy model. The GSA is used to identify the consequence and premises parameters which are used to build T-S fuzzy model. The performance of GSAHCA evaluates with some non linear system using real system sampled data sets in which GSAHCA provides better performance. The GSAHCA also compares with FCRM for identify model accuracy in which GSAHCA provides better result than FCRM.

Table 2. Comparisons of GSA and its variants to other techniques

\begin{tabular}{|c|c|c|c|c|c|c|c|c|c|c|}
\hline \multirow{2}{*}{ Method } & \multicolumn{2}{|c|}{ Iris } & \multicolumn{2}{c|}{ Wine } & \multicolumn{2}{c|}{ Glass } & \multicolumn{2}{c|}{ CMC } & \multicolumn{2}{c|}{ Cancer } \\
\cline { 2 - 11 } & Avg. & Std. & Avg. & Std. & Avg. & Std. & Avg. & Std. & Avg. & Std. \\
\hline KM & 106.05 & 14.63 & 18061.00 & 793.21 & 235.50 & 12.47 & 5893.60 & 47.16 & 3251.21 & 251.14 \\
\hline KMH & 113.41 & 0.09 & 18386.00 & $\mathbf{0 . 0 0}$ & 257.18 & $\mathbf{0 . 0 0}$ & 5852.96 & 25.00 & 3234.40 & $\mathbf{0 . 0 0}$ \\
\hline GA & 125.19 & 14.56 & 16530.53 & $\mathbf{0 . 0 0}$ & 282.32 & 4.14 & 5756.59 & 50.37 & 3249.46 & 229.73 \\
\hline SA & 99.95 & 2.02 & 17521.09 & 753.08 & 282.19 & 4.24 & 5893.48 & 50.87 & 3239.17 & 230.19 \\
\hline ACO & 97.17 & 0.37 & 16530.53 & $\mathbf{0 . 0 0}$ & 273.46 & 3.58 & 5819.13 & 45.63 & 3046.06 & 90.50 \\
\hline HBMO & 96.95 & 0.53 & 16357.28 & $\mathbf{0 . 0 0}$ & 247.71 & 2.44 & 5713.98 & 12.69 & 3112.42 & 103.47 \\
\hline PSO & 97.23 & 0.35 & 16417.47 & 85.49 & 275.71 & 4.55 & 5820.96 & 46.95 & 3050.04 & 110.80 \\
\hline GSA & $\mathbf{9 6 . 7 2}$ & $\mathbf{0 . 0 1}$ & $\mathbf{1 6 3 7 6 . 6 1}$ & $\mathbf{3 1 . 3 4}$ & $\mathbf{2 2 5 . 7 0}$ & $\mathbf{3 . 4 0}$ & $\mathbf{5 6 9 9 . 8 4}$ & $\mathbf{1 . 7 2}$ & $\mathbf{2 9 7 3 . 5 8}$ & $\mathbf{8 . 1 7}$ \\
\hline GSA-KM & $\mathbf{9 6 . 6 9}$ & $\mathbf{0 . 0 1}$ & $\mathbf{1 6 2 9 4 . 3 1}$ & $\mathbf{0 . 0 4}$ & 214.22 & 1.14 & $\mathbf{5 6 9 7 . 3 6}$ & $\mathbf{0 . 2 7}$ & $\mathbf{2 9 6 5 . 2 1}$ & 0.07 \\
\hline GSA-KMH & $\mathbf{9 6 . 5 8}$ & $\mathbf{0 . 0 0 2}$ & $\mathbf{1 6 2 3 4 . 5 6 0}$ & $\mathbf{0}$ & $\mathbf{1 8 5 . 7 1 0}$ & $\mathbf{0 . 0 3 5}$ & $\mathbf{5 6 8 5 . 3 5 0}$ & $\mathbf{0 . 3 1 0}$ & $\mathbf{2 9 5 4 . 2 5 0}$ & $\mathbf{0 . 0 5 6}$ \\
\hline GSA-HS & 96.65 & 0.0 & 16292 & 0.0 & --- & ---- & 5693.7 & 0.0 & 2964.4 & 0.0 \\
\hline PSOGSA & 97.23 & 0.060 & 16331.260 & 0.450 & $\mathbf{2 0 5 . 7 1 0}$ & 2.090 & 5699.100 & 0.540 & 2969.410 & 0.063 \\
\hline
\end{tabular}


Discussion: The study of the literature of GSA in clustering, it has been observed that five GSA based algorithms have been proposed to solve the clustering problems. These algorithms are GSA, GSA-KM, GSAKMH, GSA-HS and PSOGSA. To evaluate the relatively performance of GSA and its variant to others techniques, a table is constructed using common datasets \& parameters with help of literature $[37,78,79,80]$ and compares the GSA \& its variants to other clustering techniques. The table 2 provides the comparisons between the GSA \& its variants to other well known techniques that are used to solve the clustering problems. The performance of these techniques evaluate with five different dataset using sum of intra cluster distance \& standard deviation parameters. These para meters deduce the efficiency of techniques in data clustering. Minimum value of parameters means better the efficiency of the technique. The GSA provides minimum sum of intra cluster distance with all five datasets as compares to KM, $\mathrm{KMH}, \mathrm{GA}, \mathrm{SA}, \mathrm{ACO}, \mathrm{HBMO}$ and PSO. To analyze standard deviation parameter, GSA has minimum value for Iris and CMC datasets while second minimu m value for all other datasets. So, Table 2 states that GSA provides more accurate and significant result than other techniques except GSA variants. Table 2 also provides the comparisons of different GSA variants i.e. GSA, GSA-KM, GSA-KMH, GSA- HS and PSOGSA. From the table 2, it is conclude that GSA-KMH provides the minimum sum of intra clusters distance and GSA-HS provides almost zero value of standard deviation parameter. The quality of cluster depends on the minimum value of objects from its cluster centroid. So, minimum sum of intra cluster distance mean objects are tightly bound with cluster. From the Table 2, it is observe that GSA-KMH is the best technique among all GSA variants and other nature inspired techniques for clustering problem.

\section{GSA IN CLASSIFICATION}

Classification is the process of mapping the objects from input space to set of predefined classes and allocate the objects with one of class from set of predefined classes. There are many classification techniques that have been developed and applied on the datasets to classify the objects such as decision tree [81, 82], Artificial neural network [9, 83], ABC [11], PSO [84], Support vector machine [85] etc. Accuracy is the crucial parameter in the classification problems to test the performance of the classification techniques whether the classification techniques properly classified the instance of a datasets or not. Due to diversity in the classification problems there does not exists a single technique that has been applied on all of the classification problems. This paper enlightens the application of GSA in the classification and provided the comparisons of GSA to other techniques. Hossein Askari and Seyed-Hamid Zahiri [42] have proposed new algorith $\mathrm{m}$ based on GSA for classification problem and called it Intelligent GSA i.e. IGSA classifier. In IGSA fuzzy rule is used to modify the value of two parameters: swarm size define the number of object and gravitational coefficient of GSA. The performance of IGSA classifier compares with IPS classifier ( PSO based classifier), IGA classifier (GA) and DE based classifier (Differential Equation based classifier) with accuracy, minimum, maximum and average score of recognition including five datasets from UCI repository in which IGSA provides better performance. Abbas Bahrololoum et al. [86] has proposed a new prototype classifier based on GSA for classification problem and three different fitness function defined for this classifier to evaluate the one representative for each class. Three version of GSA classifier has been developed with the help of three fitness functions. The performance of newly build classifiers compare with PSO and ABC including 12 datasets that are taken from the UCI repository and average misclassification percentage error parameter. To improve the classification accuracy for binary problems, Soroor Sarafrazi et al [87] has proposed a new hybrid algorithm GSA-SVM based on GSA \& SVM. The performance of proposed algorithm evaluates with accuracy (standard deviation, mean, minimum \& maximum) parameter using five datasets from UCI repository and compares with PSO-SVM \& PSO-GA in which GSA-SVM provides better performance than others. To overcome parameter setting problem in SVM $\&$ increase the accuracy of feature subset selection Soroor Sarafrazi and Hossein Nezamabadi-pour [85] has proposed a new hybrid algorithm GSA-SVM based on original GSA, Binary GSA \& SVM for binary problems in which original GSA is used to setting the parameters of SVM and Binary GSA for feature subset selection. The performance of GSA evaluates with accuracy parameter (Mean \& Standard Deviation) using eight well known binary datasets from UCI repository and compares with PSO and GA-SVM in which GSA-SVM predicts data more accurately than others.

Discussion: To the depth study of GSA in classification problem, it has been observed that there exist some common data sets on which GSA \& its variants compare with other classification methods using some parameters and GSA \& its variants provides better performance than others. Such datasets are Iris, wine, glass \& cancer and performance of clas sification methods evaluate with misclassified instance, accuracy, rank parameters etc. Table $3[66,85,86,87]$ provides the comparisons of GSA \& its variants (that are proposed for classification problems) with other techniques using above discussed common datasets with two parameters: accuracy \& rank as well as some other methods also include such as ID3, J48, SVM, IBK etc.

Table 3 consists twenty two different methods that are used to solve classification problems such as GSA based classifiers i.e. original GSA classifier, IGSA Estimation \& GSA Prototype, PSO, ABC, IPS, IGA, DE, Bayes based i.e. bayes net, ANN, Tree based i.e.ID3, J48, NB tree, Function based classifiers i.e. RBF and SVM with four well defined datasets i.e. iris, cancer, wine and glass. Table 3 shows that for the Wine \& Glass datasets GSA 
variants (97.64, 97.6, 88 and 79.5) provide best result among all these techniques. For Iris and Cancer datasets ABC (100) algorithm provides the best result with both of parameters i.e. accuracy \& rank but GSA variants provide the second $\&$ third best results as shown in table 3. From the table 3, it is concludes that the overall performance of GSA variants has better than other methods. Table 4, 5, 6 shows the average accuracy results with relative ranking of all these techniques in which IGSA $(92.83,1)$, IGA $(91.33,2)$ algorithm and GSA prototype $(90.56,3)$ obtain first, second \& third position among all these techniques and the nearest competitive
ABC $(88.92,5)$ algorithm get fifth position while multi boost $(68.21,20)$ provides worst results.

Table 7, 8, 9 shows the sum of rank parameter and assign the global ranking to the techniques. Global ranking is derived from the Table 3 i.e. sum of rank that is associated with accuracy result of all techniques. According to rank parameter, IGSA, IGA \& GSA prototype has obtained first, second \& third rank while the nearest competitive ABC get forth rank and RBF \& Multi Boost get fifteenth rank means poor ones. The results of these parameters conclude that GSA variants provide remarkable results than others.

Table 3. Comparisons of accuracy \& relative ranking parameters of twenty different Techniques/classifiers

\begin{tabular}{|c|c|c|c|c|c|c|c|c|}
\hline \multirow{2}{*}{ Classifiers } & \multicolumn{2}{|c|}{ Iris } & \multicolumn{2}{|c|}{ Cancer } & \multicolumn{2}{|c|}{ Wine } & \multicolumn{2}{|c|}{ Glass } \\
\hline & Accuracy & Rank & Accuracy & Rank & Accuracy & Rank & Accuracy & Rank \\
\hline IPS-classifier & 95.3 & 9 & 95.9 & 9 & 94.9 & 6 & 70.1 & 6 \\
\hline IGA-classifier & 96.7 & 4 & 97 & 6 & 96.4 & 4 & 75.2 & 3 \\
\hline DE-classifier & 88.7 & 15 & 86.4 & 18 & 86.3 & 7 & 58.4 & 13 \\
\hline GSA-classifier & 82.6 & 19 & 80.1 & 20 & 61.3 & 17 & 88 & 1 \\
\hline IGSA-classifier & 98.1 & 2 & 96.1 & 8 & 97.6 & 2 & 79.5 & 2 \\
\hline PSO & 96.14 & 6 & 95.74 & 10 & 96.22 & 5 & 60.33 & 9 \\
\hline $\mathrm{ABC}$ & 100 & 1 & 100 & 1 & 97.19 & 3 & 58.5 & 12 \\
\hline GSA Prototype & 97.54 & 3 & 99.37 & 3 & 97.64 & 1 & 67.67 & 7 \\
\hline GSA-SVM (GSA+BGSA) & - & - & 99.54 & 2 & - & - & - & - \\
\hline GSA-SVM & - & - & 99.37 & 3 & - & - & - & - \\
\hline Bayes Net & 95.77 & 7 & 80.26 & 19 & 70.2 & 9 & 75.02 & 4 \\
\hline MLP ANN & 93.96 & 11 & 97.07 & 5 & 66.12 & 12 & 64.61 & 8 \\
\hline RBF & 91.66 & 14 & 79.33 & 21 & 60.55 & 18 & 55.56 & 14 \\
\hline K-Star & 93.26 & 13 & 97.56 & 4 & 64.22 & 14 & 60.28 & 10 \\
\hline Bagging & 96.58 & 5 & 95.53 & 13 & 63.76 & 16 & 50 & 16 \\
\hline Multi Boost & 68.4 & 20 & 93.91 & 15 & 64.22 & 14 & 46.3 & 18 \\
\hline NB Tree & 94.73 & 10 & 92.31 & 16 & 68.12 & 10 & 71.12 & 5 \\
\hline SMO (SVM) & 88.66 & 16 & 95.7 & 11 & 66.51 & 11 & 51.4 & 15 \\
\hline IBK & 85.33 & 18 & 95.56 & 12 & 65.1 & 13 & 58.87 & 11 \\
\hline Dagging & 86 & 17 & 96.7 & 7 & 64.2 & 15 & 46.72 & 17 \\
\hline $\mathrm{J} 48$ & 95.33 & 8 & 94.42 & 14 & 64.2 & 15 & 37.38 & 19 \\
\hline ID3 & 93.55 & 12 & 92.24 & 17 & 72.34 & 8 & 36.56 & 20 \\
\hline
\end{tabular}

Table 4. Average accuracy result with relative ranking of datasets

\begin{tabular}{|c|c|c|c|c|c|c|c|c|}
\hline \multirow{2}{*}{ Parameter } & \multicolumn{7}{|c|}{ Classifiers } \\
\cline { 2 - 9 } & IPS & IGA & DE & GSA & IGSA & PSO & ABC & GSA Prototype \\
\hline Average Accuracy & 89.05 & 91.33 & 79.95 & 78 & $\mathbf{9 2 . 8 3}$ & 87.11 & 88.92 & 90.56 \\
\hline Rank & 4 & 2 & 10 & 12 & $\mathbf{1}$ & 6 & 5 & 3 \\
\hline
\end{tabular}

Table 5. Average accuracy result with relative ranking of datasets

\begin{tabular}{|c|c|c|c|c|c|c|}
\hline \multirow{2}{*}{ Parameter } & \multicolumn{7}{|c|}{ Classifiers } \\
\cline { 2 - 7 } & Bayes Net & MLP ANN & RBF & K-Star & Bagging & Multi Boost \\
\hline Average Accuracy & 80.31 & 80.44 & 71.78 & 78.83 & 76.47 & $\mathbf{6 8 . 2 1}$ \\
\hline Rank & 9 & 8 & 19 & 11 & 13 & $\mathbf{2 0}$ \\
\hline
\end{tabular}


Table 6: Average accuracy result with relative ranking of datasets

\begin{tabular}{|c|c|c|c|c|c|c|}
\hline \multirow{2}{*}{ Parameter } & \multicolumn{6}{|c|}{ Classifiers } \\
\cline { 2 - 7 } & NB Tree & SMO & IBK & Dagging & J48 & ID3 \\
\hline Average Accuracy & 81.57 & 75.57 & 76.22 & 73.41 & 72.83 & 73.67 \\
\hline Rank & 7 & 15 & 14 & 17 & 18 & 16 \\
\hline
\end{tabular}

Table 7: Sum of Ranks of Techniques \& Global Ranking

\begin{tabular}{|c|c|c|c|c|c|c|c|c|}
\hline \multirow{2}{*}{ Sum of Ranks } & \multicolumn{7}{|c|}{ Classifiers } \\
\cline { 2 - 9 } & IPS & IGA & DE & GSA & IGSA & PSO & ABC & GSA Prototype \\
\hline Sum of Ranks & $29(6)$ & $16(3)$ & $52(11)$ & $56(14)$ & $12(1)$ & $19(5)$ & $17(4)$ & $13(2)$ \\
\hline
\end{tabular}

Table 8: Sum of Ranks of Techniques \& Global Ranking

\begin{tabular}{|c|c|c|c|c|c|c|}
\hline \multirow{2}{*}{ Sum of Ranks } & \multicolumn{6}{|c|}{ Classifiers } \\
\cline { 2 - 8 } & Bayes Net & MLP ANN & RBF & K-Star & Bagging & Multi Boost \\
\hline Sum of Ranks & $38(8)$ & $35(7)$ & $66(15)$ & $40(9)$ & $49(10)$ & $66(15)$ \\
\hline
\end{tabular}

Table 9: Sum of Ranks of Techniques \& Global Ranking

\begin{tabular}{|c|c|c|c|c|c|c|}
\hline \multirow{2}{*}{ Sum of Ranks } & \multicolumn{9}{|c|}{ Classifiers } \\
\cline { 2 - 8 } & NB Tree & SMO & IBK & Dagging & J48 & ID3 \\
\hline Sum of Ranks & $40(9)$ & $52(11)$ & $53(12)$ & $55(13)$ & $55(13)$ & $56(14)$ \\
\hline
\end{tabular}

\section{CONCLUSION}

This paper presents the review of pervious research in the field of gravitational search algorithm, its variants; hybridize GSA and its applications. Table 1 provides the complete summary of GSA literature, modification in GSA and applications of GSA. From the table 1, it conclude that GSA is four years old but this field shows tremendous growth \& quite popular between researchers and large number of problems solved by GSA such as RPDP, ED, OPF and many more mentioned in table 1. The figure 1 shows the percentage of hybrid algorithms and modification in GSA has been proposed by various authors in GSA literature. The modification and hybridization of GSA with other techniques provided better results in terms of computational time, convergence etc. The figure 3 provides the year wise development in the field of gravitational algorithms and number of publications in each year published with the help of GSA. From the figure 3, it's conclude that there is only one publication on GSA in year 2009 but in last two years large number of papers published using GSA that shows the wide popularity of GSA among researchers. The figure 4 categorizes the publications based on GSA in different domains. The figure 4 states that half of GSA publications related to computer science and computing filed that shows the GSA applicability and significance in computer science \& computing field. The twenty four percent of GSA publications come from optimization \& others field and very less publication from civil \& mechanical field. From the figure 4 , it is conclude that GSA is widely used in computer science \& computing field but a very less publications from civil \& mechanical fields.

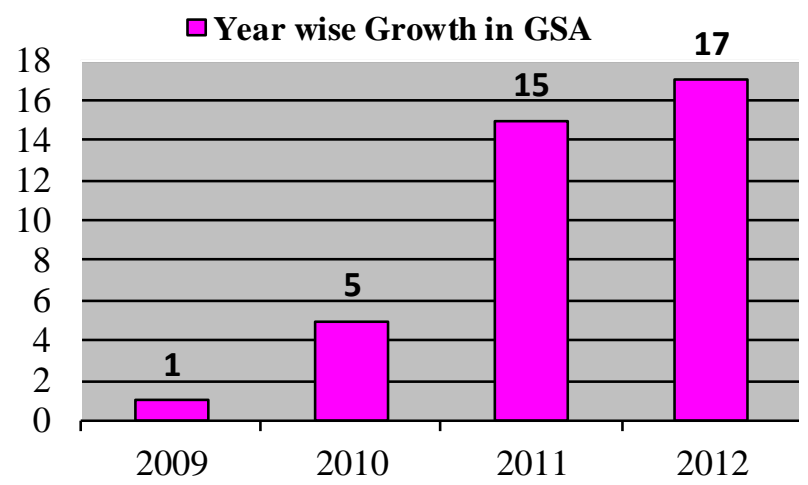

Fig. 3. Year wise growth in GSA

Figure 4 exhibits that GSA is widely use in computer science \& computing field but this field contains large number of subfields to pursue further research such as networks, security, ANN, pattern recognitions, clod computing, data mining etc. The figure 5 shows the applicability of GSA based publications in computer science \& computing field. Figure 5 articulates that more than fifty percent publications of GSA in computer science \& computing field belong to data mining domain. Data mining process defined by three terms i.e. classification, clustering and feature sub selection. The depth study of GSA shows that large number of 
algorithm proposed with the help of GSA for classification \& clustering problems in data mining domain. Table $2 \& 3$ provides comparisons of other techniques to GSA \& its variants for clustering \& classification problems in data mining respectively. From the table $2 \& 3$, it is conclude that GSA provides the better performance than others. From the section $2 \& 3$ and table $2 \& 3$, it is conclude that GSA has good potential to solve data clustering \& classification problems than other nature inspired techniques as well as conventional methods but sometime suffers from large computational time. There are several advantages of GSA that proves its significance. First, it requires only two parameters to adjust i.e. mass \& velocity of particles and second is ability to find near global optimum solution. The ability to find near global optimum solution makes the GSA differ from other nature inspired algorith ms. But the GSA is also suffers from several problems such as computational time, convergence problem if initial population not generated well. But these problems of GSA removed by the hybridization of GSA. Another thing that must be point, there is no theoretical work on the computational time and convergence of GSA these work must be perform. In this review, it is notice that there are some other areas that are not touch by the GSA. Few of these are security application, analysis of time series data, applicability of the GSA in dynamic \& uncertain environment, gene expressions, protein legend etc.

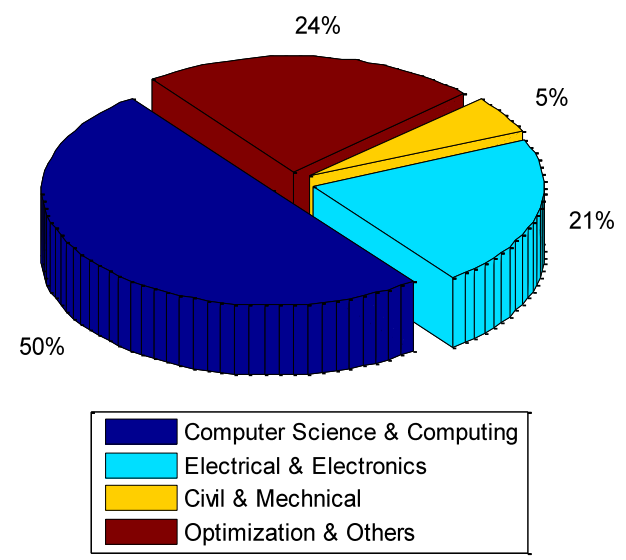

Fig. 4. Categorization of GSA publications

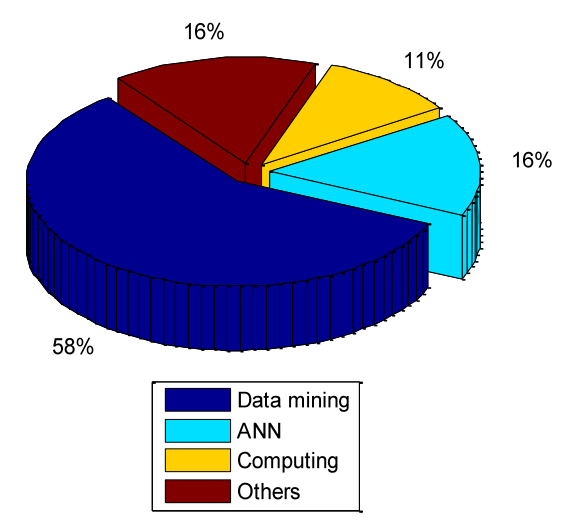

Fig. 5. GSA in computer science \& computing field

\section{REFERENCES}

[1] W. Du, B. Li,"Multi-strategy ensemble particle swarm optimization for dynamic optimization", Information Sciences, 2008, 178, pp 3096-3109.

[2] X. Yao, Y. Liu, G. Lin,'Evolutionary programming made faster", IEEE Transactions on Evolutionary Computation, 1999, 3 pp 82-102.

[3] Y. Liu, Z. Yi, H. Wu, M. Ye, K. Chen, “A tabu search approach for the minimum sum-of-squares clustering problem", Information Sciences, 2008, 178, 2680-2704.

[4] X. Tan, B. Bhanu, "Fingerprint matching by genetic algorithms", Pattern Recognition, 2006, 39, 465-477.

[5] T.H. Kim, I. Maruta, T. Sugie,"Robust PID controller tuning based on the constrained particle swarm optimization", Automatica, 2008, 44, 1104-1110.

[6] Z. Baojiang, L. Shiyong,"Ant colony optimization algorithm and its application to neuro-fuzzy controller design", Journal of Systems Engineering and Electronics $18,603-610$.

[7] O. Cordon, S. Damas, J. Santamarı,"A fast and accurate approach for 3D image registration using the scatter search evolutionary algorithm, Pattern Recognition Letters, 2006, 27 ,pp 1191-1200.

[8] H. Nezamabadi-pour, S. Saryazdi, E. Rashedi," Edge detection using ant algorithms", Soft Computing, 2006, 10, pp 623-628.

[9] JY Wu,'MIMO CMAC neural network classifier for solving classification problems", Applied Soft Computing, 2011, 11 (2), pp 2326-2333

[10] Kalinlia A, Karabogab N, "Artificial immune algorithm for IIR filter design", Engineering Applications of Artificial Intelligence, 2005, 18, 919-929.

[11] D. Karaboga, C. Ozturk (2011) A novel clustering approach: artificial bee colony (ABC) algorithm. Applied Soft Computing 11 (1), pp 652-657.

[12] Kirkpatrick S, Gelatt CD and Vecchi P,"Optimization by simulated annealing", Science, 1983, 220, 671-680.

[13] Mitra D, Romeo F and Vincentelli, A.S., "Convergence and Finite-Time Behavior of Simulated Annealing Advances in Applied Probability”, 1986.

[14] Janson S \& Middendorf M, "A hierarchical particle swarm optimizer for dynamic optimization problems", In: Proceedings of the application of evolutionary computing, 2004, volume 3005. pp 513-524.

[15] Kennedy J \& Eberhart R, "Particle swarm optimization", In: Proceeding of IEEE int'l. Conf. on neural networks, 1995, Vol. IV, pp. 1942-1948.

[16] Silva A, Neves A, Costa E,"Chasing the swarm: a predator pray approach to function optimization", In: Proceeding of the international conference on soft computing MENDEL, 2002.

[17] Y.L. Lin, W.D. Chang, J.G. Hsieh,"A particle swarm optimization approach to nonlinear rational filter modeling, Expert Systems with Applications, 2008, 34, pp 11941199.

[18] Holland JH, "Adaptation in natural and artificial systems", University of Michigan Press, 1975.

[19] Boerin ger D-W, Werner DH, "Particle swarm optimization versus gen etic algorithm for phased array synthesis", IEEE Trans Antennas Propag., 2004, 52(3):771-779.

[20] Dorigo M,"Optimization, learning and natural algorithms", $\mathrm{PhD}$ thesis, Dipartimento di Elettronica, Politecnico di Milano, Italy, 1992.

[21] Dorigo $M$ and Gambardella LM, "Ant colony for the traveling salesman problem”, Bio systems, 1997, 43, pp. 73-81. 
[22] Costa, D. and Hertz, A. (1997) Ants can color graphs. J. Operate Res. Soc., 48, pp. 295-305.

[23] Di Caro G. and Dorigo M. (1998) Two ant colony algorithms for best-effort quality of service routing. In: Unpublished at ANTS'98-From Ant Colonies to Artificial Ants: First International Workshop on Ant Colony Optimization.

[24] Merkle D \& Middendorf M.Modelling," ACO: Composed permutation problems", In: Ant algorithms Proceedings of ANTS 2002-Third international workshop. Lecture Notes in Comput Sci, 2002, vol, 2463., pp. 149-62.

[25] Gutjahr WJ, "A graph-based ant system and its convergence Future Generat. Comput. Syst., 2000, 16(9):873-88.

[26] Gutjahr WJ, "ACO algorithms with guaranteed convergence to the optimal solution", Information Process Letters, 2002, 82(3), 145-53.

[27] Karaboga D, Basturk B,"A powerful and efficient algorithm for numerical function optimization:artificial bee colony (abc) algorithm", J Glob Optim. 2007b, 39:459-471.

[28] Karaboga D \& Basturk B,"A comparative study of artificial bee colony algorithm", Applied Mathematics and Computation, 2009, 214:108-32.

[29] Akay B, Karaboga D , "A modified artificial bee colony algorithm for real-parameter optimization” Inf Sci., 2010 doi:10 .1016/j.ins.2010.07.015.

[30] Basturk B, Karaboga D, "An artificial bee colony (abc) algorithm for numeric function optimization', In: IEEE swarm intelligence symposium 2006, Indianapolis, IN, USA.

[31] Mezura-Montes E, Damian-Araoz M, Cetina-Domingez $\mathrm{O}$," Smart flight and dynamic tolerances in the artificial bee colony for constrained optimization", In: 2010 IEEE congress on evolutionary computation (CEC), 2010, pp 18 .

[32] Eduardo Gerhardt and Herbert Martins Gomes, "Artificial Bee Colony (ABC) Algorithm for Engineering Optimization", Problems In: Proceeding of $3^{\text {rd }}$ International Conference on Engineering Optimization Rio de Janeiro, Brazil, 2012.

[33] Zhu GP \& Kwong S,"Gbest-guided artificial bee colony algorithm for numerical function optimization", Applied Mathematics and Computation 2010, doi: 10.1016/j.amc.2010 .08.049.

[34] Osman K. Erol and Ibrahim Eksin,"A new optimization method: Big Bang-Big Crunch", Advances in Engineering Software, 2006, 37, pp. 106-111.

[35] Hesheng Tang, Jin Zhou, Songtao Xue and Liyu Xie, ”Big Bang-Big Crunch optimization for parameter estimation in structural systems", Mechanical Systems and Signal Processing, 2010, 24, pp 2888-2897.

[36] M.H. Afshar and I. Motaei,"CONSTRAINED BIG BANG-BIG CRUNCH ALGORITHM FOR OPTIMAL SOLUTION OF LARGE SCALE RESERVOIR OPERATION PROBLEM", Int. J. Optim. Civil Eng., 2011, 2, pp 357-375.

[37] Hatamlou A, Abdullah S and Othman Z , "Gravitational Search Algorithm with Heuristic Search for Clustering Problems", In proceeding of 3rd IEEE on Data Mining and Optimization (DMO), 2011, pp. no. 190 - 193, 28-29 June 2011, Selangor, Malaysia.

[38] Rashedi E, Nezamabadi-pour H, Saryazdi S," GSA: a gravitational search algorithm", Information Science, 2009, $179,2232-2248$.

[39] Holliday D, Resnick R and Walker J, "Fundamentals of physics", John Wiley and Sons, 1993.
[40] Schutz B.," Gravity from the Ground Up", Cambridge University Press, 2000.

[41] Rashedi E, Nezamabadi-pour H, Saryazdi S ,"BGSA: binary gravitational search algorithm", Nat Comput, 2010, 9, pp 727-745.

[42] Hamid Reza Hassanzadeh and Modjtaba Rouhani, "A MULTI OBJECTIVE GRAVITATIONAL SEARCH ALGORITHM", In: Proceeding of Second International Conference on Computational Intelligence, Communication Systems and Networks, 2010, pp.7-12.

[43] S. Sarafrazi, H. Nezamabadi-pour and S. Saryazdi, "Disruption: A new operator in gravitational search algorithm. Scientia Iranica D, 2011, 18 (3), pp. 539-548.

[44] M. Soleimanpour-mogh adam, H. Nezamabadi-pour, M. M Farsangi ,"A quantum behaved gravitational search algorithm", In: proceeding of Int. Conf. Computational Intelligence and Software Engineering, Wuhan, China, 2011.

[45] Radu-Emil Precup, Radu-Codruţ David, Emil M. Petriu , Stefan Preitl and Mircea-Bogdan Rădac,"Gravitational Search Algorithm in Fuzzy Control Systems Tuning", In: Proceeding of 18th IFAC World Congress, 2011, pp. no. 13624-13629, Milano (Italy).

[46] Nihan Kazak and Alpaslan Duysak,'Modified Gravitational Search Algorithm", In: Proceeding of IEEE International Symposium on Innovations in Intelligent Systems and Applications (INISTA), 2012, pp. 1- 4, Turkey.

[47] Mohadeseh Soleimanpour moghadam \& Hossein Nezamabadi pour, "An improved quantum behaved gravitational search algorithm", In: proceeding of 20th Iranian Conference on Electrical En gineering, (ICEE2012), 2012, pp. no. $711-715$.

[48] Nanji H. R., Mina Sohrabi and Esmat Rashedi,"A HighSpeed, Performance-Optimization Algorithm Based on a Gravitational Approach", Journal of Computing in Science \& Engineering, 2012, volume 14, Issue: 5 pp. 56-62.

[49] Xiangtao Li, Jianan Wang, Junping Zhou and Minghao Yin,”An Effective GSA Based Memetic Algorithm for Permutation Flow Shop Scheduling. In: proceeding of IEEE congress on Evolutionary Computation, 2010, pp. no $1-6$.

[50] Seyedali Mirjalili and Siti Zaiton Mohd Hashim," A new hybrid PSOGSA algorithm for function optimization", In: Proceeding of International conference on computer and information application (ICCIA), 2010, pp. no. 374- 377.

[51] Chatterjee A, Mahanti G. K. and Pathak N, (2010)," COMPARATIVE PERFORMANCE OF GRAVITATIONAL SEARCH ALGORITHM AND MODIFIED PARTICLE SWARM OPTIMIZATION ALGORITHM FOR SYNTHESIS OF THINNED SCANNED CONCENTRIC RING ARRAY ANTENNA", Progress In Electromagnetic Research B, Vol. 25, 331-348.

[52] Radu-Emil Precup, Radu-Codruț David, Emil M. Petriu , Stefan Preitl and Adrian Sebastian Paul,"Gravitational Search Algorithm-Based Tuning of Fuzzy Control Systems with a Reduced Parametric Sensitivity", Advances in Intelligent and Soft Computing, 2011, Volume 96, pp. 141-150.

[53] Jianhua Xiao, Fan Qi, and Yongkai Li, "Gravitational Chaotic Search Algorithm for Partners Selection with Due Date Constraint in Virtual Enterprise", In: Proceed ing of Fourth International Workshop on Advanced Computational Intelligence, 2011, pp. $138-142$.

[54] J. P. Papa, A. Pagnin, S. A. Schellini, A. Spadotto, R. C. Guido, M. Pont, G. Chiachia and A. X. 
Falcaoi,"FEATURE SELECTION THROUGH GRAVITATIONAL SEARCH ALGORITHM", In: Proceeding of IEEE international conference Acoustics, Speech and Signal Processing (ICASSP), 2011, pp. 2052 $-2055$.

[55] M. Ghalambaz, A.R. Noghrehabadi, M.A. Behrang, E. Assareh, A. Ghanbarzadeh, N.Hedayat,"A Hybrid Neural Network and Gravitational Search Algorithm (HNNGSA) Method to Solve well known Wessinger's Equation", World Academy of Science, En gineering and Technology, 2011, issue 49, pp. no. $803-807$.

[56] Chaoshun $\mathrm{Li}$ and Jianzhong Zhou , "Parameters identification of hydraulic turbine governing system using improved gravitational search algorithm", Energy Conversion and Management, 2011, Volume 52, Issue 1, pp. 374-381.

[57] Jianhua Xiao and Zhen Cheng,'DNA Sequences Optimization Based on Gravitational Search Algorithm for Reliable DNA computing In: proceeding of IEEE Sixth International Conference on Bio-Inspired Computing: Theories and Applications, 2011, pp. $103-107$.

[58] Esmat Rashedi, Hossien Nezamabadi-pour and Saeid Saryazdi,"Filter modeling using gravitational search algorithm Engineering applications of Artificial Intelligence, 2011, volume 24(1), pp 117-122.

[59] [59] Serhat DUMAN, Aysen Basa ARSOY and Nuran YÖRÜKEREN ,"Solution of Economic Dispatch Problem using Gravitational Search Algorithm", In: Proceeding of $7^{\text {th }}$ international conference of electrical and electronics engineering, 2011, pp.54-59, Turckey.

[60] Chaoshun Li, Jianzhong Zhou, Jian Xiao and Han Xiao (2012)Parameters identification of chaotic system by chaotic gravitational search algorithm. Chaos, Solitons \& Fractals, Volume 45, Issue 4, Pages 539-547, 2012.

[61] Radu-Emil Precup, Radu-Codruţ David, Emil M. Petriu , Stefan Preitl and Mircea-Bogdan Radac,'Novel Adaptive Gravitational Search Algorithm for Fuzzy Controlled Servo Systems", IEEE Transcation on Industrial Informatics, 2012, volume 8, no. 4, pp 791 -800.

[62] Lucian Ovidiu Fedorovici, Radu-Emil Precup, Florin Dragan, Radu-Codrut David and Constantin Purcaru ,"Embedding Gravitational Search Algorithms in Convolutional Neural Networks for OCR Applications In: Proceeding of 7 th IEEE International Symposium on Applied Computational intelligence and Informatics, 2012, pp. $125-130$.

[63] S. Duman, Y. So nmez, U. Gu venc and N. Yo ru keren, "Optimal reactive power dispatch using a gravitational search algorithm", IET Gener. Transm. Distrib., 2012, Vol. $6(6)$, pp. 563-576.

[64] Serhat Duman, Ugur Guvenc, Yusuf Sonmez and Nuran Yorukeren,"Optimal power flow using gravitational search algorithm", Energy Conversion and Management, 2012, volume 59, pp 86-95.

[65] Asrulibrahim A, Mohamed and Shareef H, "Application of quantum-inspired binary gravitational search algorithm for optimal power quality monitor placement. In: proceedings of the $11^{\text {th }}$ WSEAS international conference on Artificial Intelligence, Knowledge Engineering and Database,", 2012, pp. no. 27- 32.

[66] Hossein Askari and Seyed-Hamid Zahiri, "Decision function estimation using intelligent gravitational search algorithm", Int. J. Mach. Learn. \& Cyber, 2012, 3, pp. 163-172.

[67] Mohammad Khajehzadeh, Mohd RaihanTaha, Ahmed ElShafie and MahdiyehEslami, "A modified gravitational search algorithm for slope stability analysis", Engineering Applications of Artificial Intelligence (article in press)

[68] Hamed Sadeghi, Najmeh Eghbal and Reyhaneh Kardehi Moghaddam, "Application Gravitational Search Algorithm in Identification of Switched Linear Systems", In: Proceeding of IEEE Third International Conference on Intelligent Systems Modeling and Simulation, 2012, pp. $89-95$.

[69] LI Pei \& Duan HaiBin,'Path planning of unmanned aerial vehicle based on improved gravitational search algorithm", Science China published by Springer, 2012, Vol.55 No.10: 2712-2719.

[70] M. Mahdavi (2008) Novel meta-heuristic algorithms for clustering web documents. Applied Mathematics and Computation, 208, 201 (1-2), pp 441-451.

[71] R. Gil-Garcia, A. Pons-Porrata,"Dynamic hierarchical algorithms for document clustering, Pattern Recognition Letters, 2010, 31 (6), pp 469-477.

[72] Tan P N, Steinbach M \& Kumar, "Introduction to data mining, Boston: Addison Wesley, 2005, pp.487-559.

[73] Tjhi W C \& Chen L H,"A heuristic-based fuzzy coclustering algorithm for categorization of highdimensional data”, Fuzzy Sets and Systems, 2008, 159(4), pp 371-389.

[74] P. Jin, Y.L. Zhu, K.Y. Hu,"A clustering algorithm for data mining based on swarm intelligence", in: Proceedings of the Sixth International Conference on Machine Learning and Cybernetics, ICMLC, 2007.

[75] Zhang B, Hsu M \& Dayal U,'K-harmonic means - a data clustering algorithm", Technical Report HPL-1999-124, Hewlett-Packard Laboratories.

[76] P.S. Shelokar, V.K. Jayaraman, B.D. Kulkarni, "An ant colony approach for clustering", Analytica Chimica Acta, 2004, 509 (2),pp 187-195.

[77] Zhou H \& Liu YH,"Accurate integration of multi-view range images using k-means clustering. Pattern Recognition, 2008, 41(1), pp 152-175.

[78] Hatamlou A, Pour HN and Abdullah S, " Application of gravitational search algorithm on data clustering In: published in proceeding of $6^{\text {th }}$ international workshop on Rough Set and Knowledge technology (RSKT-11), 2011, pp. no. 337-346.

[79] Hatamlou A, Abdullah S and Pour HN, “ A combined approach for clustering based on K-means and gravitational search algorithms", Swarm and Evolutionary Computation, 2012, 6, pp 47-52.

[80] Minghao Yin, Yanmei Hu, Fengqin Yang, Xiangtao Li and Wenxiang Gu,"A novel hybrid K-harmonic means and gravitational search algorithm approach for clustering", Expert Systems with Applications, 2011, 38, 9319-9324.

[81] M.W. Kurzynski, "The optimal strategy of a tree classifier", Pattern Recognition, 1983, 16, pp 81-87.

[82] F. Seifi, M.R. Kangavari, H. Ahmadi, E. Lotfi, S. Imaniyan, S. Lagzian, "Optimizing twins decision tree classification using genetic algorithms", In: 7th IEEE International Conference on Cybernetic Intelligent Systems, 2008, pp. 1-6.

[83] P. Knagenhjelm, P. Brauer,"Classification of vowels in continuous speech using MLP and a hybrid network", Speech Communication,1990, 9 (1) pp 31-34.

[84] Rana S, Jasola S and Kumar R A review on particle swarm optimization algorithms and their applications to data clustering Artif Intell Rev, 201,1 35, 211-222.

[85] Soroor Sarafrazi and Hossein Nezamabadi-pour, "Facing the classification of binary problems with a GSA-SVM hybrid system", Mathematical and Computer Modeling, 2013, vol. 57, issue 1, pp. 270-278. 
[86] Bahrololoum A, Pour HN, Bahrololoum H and Saeed M, "A prototype classifier based on gravitational search algorithm", Applied Soft Computing, 2012, 12, 819-825.

[87] Soroor Sarafrazi, Hossein Nezamabadi-pour and Mojgan Barahman,"A GSA-SVM HYBRID SYSTEM FOR CLASSIFICATION OF BINARY PROBLEMS", In: Proceedings of the Fourth Global Conference on Power Control and Optimization, 2011, pp. 198-203.

\section{Author's Profile:}

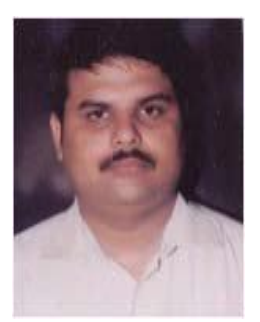

Yugal Kumar received his B.Tech in IT information Technology from Maharishi Dayanand University, Rohtak, (India) in 2006 \& M.Tech in Computer Engineering from same in 2009. At present, he is pursuing Ph.D. in Department of Information Technology at Birla Institute of Technology, mesra, Ranchi, India. His research interests include fuzzy logic, computer network, Data Mining and Swarm Intelligence.

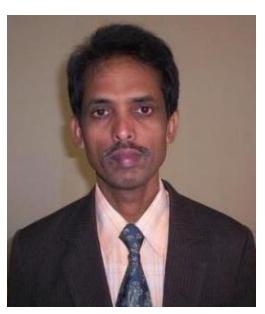

G. Sahoo received his $\mathrm{MSc}$ in Mathematics from Utkal University in the year 1980 and $\mathrm{PhD}$ in the Area of Computational Mathematics from Indian Institute of Technology, Kharagpur in the year 1987. He has been associated with Birla Institute of Technology, Mesra, Ranchi, India since 1988, and currently, he is working as a Professor and Head in the Department of Information Technology. His research interest includes theoretical computer science, parallel and distributed computing, cloud computing, evolutionary computing, information security, image processing and pattern recognition.

How to cite this paper: Yugal kumar, G. Sahoo,"A Review on Gravitational Search Algorithm and its Applications to Data Clustering \& Classification", International Journal of Intelligent Systems and Applications(IJISA), vol.6, no.6, pp.79-93, 2014. DOI: 10.5815/ijisa.2014.06.09 